\title{
Gynura procumbens Root Extract Ameliorates Ischemia-Induced Neuronal Damage in the Hippocampal CA1 Region by Reducing Neuroinflammation
}

\author{
Woosuk Kim ${ }^{1,2}$, Hyo Young Jung ${ }^{1}{ }^{(D)}$, Dae Young Yoo ${ }^{3}{ }^{\circledR}$, Hyun Jung Kwon ${ }^{4}$, Kyu Ri Hahn ${ }^{1}$, Dae Won Kim ${ }^{4} \mathbb{D}$, \\ Yeo Sung Yoon ${ }^{1}$, Soo Young Choi ${ }^{2, *}$ and In Koo Hwang ${ }^{1, *(\mathbb{D}}$
}

1 Department of Anatomy and Cell Biology, College of Veterinary Medicine, and Research Institute for Veterinary Science, Seoul National University, Seoul 08826, Korea; tank3430@hallym.ac.kr (W.K.); hyoyoung@snu.ac.kr (H.Y.J.); hkinging@snu.ac.kr (K.R.H.); ysyoon@snu.ac.kr (Y.S.Y.)

2 Department of Biomedical Science and Research Institute for Bioscience and Biotechnology, Hallym University, Chuncheon 24252, Korea

3 Department of Anatomy, College of Medicine, Soonchunhyang University, Cheonan 31151, Korea; dyyoo@sch.ac.kr

4 Department of Biochemistry and Molecular Biology, Research Institute of Oral Sciences, College of Dentistry, Gangneung-Wonju National University, Gangneung 25457, Korea; donuts25@gwnu.ac.kr (H.J.K.); kimdw@gwnu.ac.kr (D.W.K.)

* Correspondence: sychoi@hallym.ac.kr (S.Y.C.); vetmed2@snu.ac.kr (I.K.H.)

\section{check for}

updates

Citation: Kim, W.; Jung, H.Y.; Yoo, D.Y.; Kwon, H.J.; Hahn, K.R.; Kim, D.W.; Yoon, Y.S.; Choi, S.Y.;

Hwang, I.K. Gynura procumbens Root Extract Ameliorates Ischemia-Induced Neuronal Damage in the Hippocampal CA1 Region by Reducing Neuroinflammation. Nutrients 2021, 13, 181. https://doi.org/10.3390/ nu13010181

Received: 1 December 2020 Accepted: 5 January 2021 Published: 8 January 2021

Publisher's Note: MDPI stays neutral with regard to jurisdictional clai$\mathrm{ms}$ in published maps and institutional affiliations.

Copyright: $(\odot 2021$ by the authors. Licensee MDPI, Basel, Switzerland. This article is an open access article distributed under the terms and conditions of the Creative Commons Attribution (CC BY) license (https:// creativecommons.org/licenses/by/ $4.0 /)$.

\begin{abstract}
Gynura procumbens has been used in Southeast Asia for the treatment of hypertension, hyperglycemia, and skin problems induced by ultraviolet irradiation. Although considerable studies have reported the biological properties of Gynura procumbens root extract (GPE-R), there are no studies on the effects of GPE-R in brain damages, for example following brain ischemia. In the present study, we screened the neuroprotective effects of GPE-R against ischemic damage and neuroinflammation in the hippocampus based on behavioral, morphological, and biological approaches. Gerbils received oral administration of GPE-R (30 and $300 \mathrm{mg} / \mathrm{kg}$ ) every day for three weeks and $2 \mathrm{~h}$ after the last administration, ischemic surgery was done by occlusion of both common carotid arteries for $5 \mathrm{~min}$. Administration of $300 \mathrm{mg} / \mathrm{kg}$ GPE-R significantly reduced ischemia-induced locomotor hyperactivity 1 day after ischemia. Significantly more NeuN-positive neurons were observed in the hippocampal CA1 regions of $300 \mathrm{mg} / \mathrm{kg}$ GPE-R-treated animals compared to those in the vehicle-treated group 4 days after ischemia. Administration of GPE-R significantly reduced levels of pro-inflammatory cytokines such as interleukin-1 $\beta,-6$, and tumor necrosis factor- $\alpha 6 \mathrm{~h}$ after ischemia/reperfusion. In addition, activated microglia were significantly decreased in the $300 \mathrm{mg} / \mathrm{kg}$ GPE-R-treated group four days after ischemia/reperfusion compared to the vehicle-treated group. These results suggest that GPE-R may be one of the possible agents to protect neurons from ischemic damage by reducing inflammatory responses.
\end{abstract}

Keywords: Gynura procumbens root extract; neuroprotection; pro-inflammatory cytokines; microglia; ischemia

\section{Introduction}

Transient interruption of blood supply to the brain, referred to as transient forebrain ischemia, causes neuronal loss in the striatum, somatosensory cortex, and hippocampus [1,2]. Ischemic damage manifests as different phenotypes depending on the time post-injury and the affected regions. Mongolian gerbil (Meriones unguiculatus) is one of the most useful animals to induce transient forebrain ischemia because of its incomplete connections between basilar and internal carotid arteries at the base of the brain [3,4]. In this animal, damage to the hippocampus causes locomotor hyperactivity one day after ischemia/reperfusion 
and cognitive impairments by neuronal death in the pyramidal cells four days after ischemia [5-9]. The transient ischemia and subsequent reperfusion significantly increase the oxygen free radicals and induce neuronal damage in the hippocampus [10,11]. In addition, neuroinflammation induced by ischemic neuronal death activates microglia in the affected regions, which secrete pro-inflammatory cytokines such as interleukin (IL)-1 $\beta$, IL-6, and tumor necrosis factor- $\alpha$ (TNF- $\alpha$ ) $[12,13]$. Increased expression of IL-1 $\beta$ and TNF- $\alpha$ can facilitate the disruption of the blood-brain barrier and accelerate the formation of edema in the brain [14]. Many individuals suffer from transient forebrain ischemia each year, and survivors are often left with disabilities including long-term sensorimotor deficits and cognitive impairment $[15,16]$. However, to date, there is no effective treatment for transient forebrain ischemia [17].

Gynura procumbens belongs to the family of Asteraceae and its leaves have been used in folk medicine for the improvement of various types of illnesses and diseases [18] because it is non-toxic when consumed [19]. For example, an extract from Gynura procumbens leaves (GPE-L) decreases blood glucose levels and systolic blood pressure [20-24] and significantly reduces heart rate and atrial contractility [25,26]. In addition, GPE-L has antioxidant effects that reduce the generation of ultraviolet irradiation-induced reactive oxygen species and the expression of metalloproteinases in human dermal fibroblasts [27]. Whole plant extract of Gynura procumbens reduces the oxidative stress and damage in membrane by modulating the antioxidants [28]. However, in a recent study, GPE-L showed no reduction of oxidative stress and very low antioxidant activity in in vitro assay [18]. Another recent study showed that GPE petroleum ether extract could reduce the formation of oxygen radical species in vessels by inducing the vasodilation [29]. An extract from Gynura procumbens roots (GPE-R) with abundant content of phenolic, flavonoid compounds, and ascorbic acid, has shown higher antioxidant capacities than GPE-L [18], suggesting that it may also have therapeutic benefits. In addition, treatment with GPE-L facilitates the healing process in tissue wounds by reducing inflammatory processes [30]. Despite GPE having been studied for its biological effects, including antioxidant and anti-inflammatory effects, there have been no studies on GPE effects on cellular damage induced by transient forebrain ischemia [31].

In this study, we examined the potential ameliorative effects of GPE-R on neuronal damage in Mongolian gerbils, at 4 days after inducing transient forebrain ischemia.

\section{Materials and Methods}

\subsection{Experimental Animals}

Sixty male gerbils ( $6 \pm 0.5$ months of age; $67 \pm 4.3 \mathrm{~g}$ body weight) were used in the study. Animals were purchased from Japan SLC Inc. (Shizuoka, Japan) and mated each other. Only male gerbils were selected because they show larger infarct size, higher inflammatory responses, and increased activation of microglia after the ischemic insult [32]. Animals were housed in cages (four gerbils per cage) in a conventional area under standard conditions as described previously [33,34]. The experimental procedure was conducted according to international standards [35] and the protocol was approved by ethical committee (SNU-170807-11).

\subsection{Preparation of GPE- $R$}

For GPE-R, roots of Gynura procumbens (100 g) were purchased from a local oriental herb market (Kyung Dong Si Jang, Seoul, Korea). Roots of Gynura procumbens were ground, dried, and macerated using $80 \%$ ethanol (3 times) for $72 \mathrm{~h}$ at $20{ }^{\circ} \mathrm{C}$, and washed with distilled water at $20^{\circ} \mathrm{C}$ for $2 \mathrm{~h}$. The extract was filtered using Whatman No.1 filter paper (Whatman, Maidstone, UK) and the insoluble materials were eliminated by centrifugation at $10,000 \times g$ for $30 \mathrm{~min}$ at $20^{\circ} \mathrm{C}$. The residual solvent was removed using rotary evaporator at $40{ }^{\circ} \mathrm{C}$ and the extract was freeze-dried. The final yield of was $9.49 \%$. 


\subsection{Administration of GPE-R}

The gerbils were divided into four groups: control group, vehicle-treated ischemic group, $30 \mathrm{mg} / \mathrm{kg}$ GPE-R-treated ischemic group, and $300 \mathrm{mg} / \mathrm{kg}$ GPE-R-treated ischemic group. Gerbils received oral administration of distilled water (vehicle-treated ischemic group) or GPE-R ( $30 \mathrm{mg} / \mathrm{kg}$ and $300 \mathrm{mg} / \mathrm{kg}$ GPE-R-treated ischemic groups) with a feeding needle once a day for 3 weeks before the surgery. Doses of GPE-R were chosen based on previous findings which showed that administration of $150-450 \mathrm{mg} / \mathrm{kg}$ of GP aqueous extract improved fertility [36] and administration of $25-50 \mathrm{mg} / \mathrm{kg}$ of GP stem extract (GPE-S) ameliorated ethanol-induced steatosis [37].

\subsection{Ischemic Surgery}

Ischemic surgery was conducted as described previously [32,33]. The animals were anesthetized with a mixture of $2.5 \%$ isoflurane (Hana Pharmaceutical Co., Ltd., Seoul, Korea) $[38,39]$ in $33 \%$ oxygen and $67 \%$ nitrous oxide $1 \mathrm{~h}$ after the last vehicle or GPE$\mathrm{R}$ treatment. The ventral neck region was shaved and a midline incision was made. Common carotid arteries were freed from the vagosympathetic trunk and isolated with Chromic Catgut \#4. Occlusion of both arteries was done by non-traumatic aneurysm clips for $5 \mathrm{~min}$ and reperfusion was confirmed to observe the current flow of retinal central artery using an ophthalmoscope (HEINE K180 ${ }^{\circledR}$; Heine Optotechnik, Herrsching, Germany). Bilateral common carotid occlusion was not performed in the control group (sham-operated). Animals after ischemic surgery were kept on the thermal incubator to maintain the body temperature without treatment with analgesics until they were euthanized because opioid agonists, anti-inflammatory drugs, and dexmedetomidine show neuroprotection against ischemic damage [40-43]. In addition, acetaminophen protects the brain tissue after middle cerebral artery occlusion, and thus should not be used to induce analgesia in rodents subjected to experimental stroke [43]. After ischemic surgery, animals were carefully monitored at least 4 times a day to identify animal welfare before reaching humane endpoint as described by Percie du Sert et al. [44]. Animals were sacrificed when the animals showed reduction of body weight $(>20 \%)$, complete anorexia for $24 \mathrm{~h}$, partial anorexia ( $<50 \%$ food intake) for 3 days, and inability and severe reluctance to stand for $24 \mathrm{~h}$. In addition, animals were sacrificed when the animals show severe depression, lack of movement, and hypothermia.

\subsection{Locomotor Activity}

To observe the effects of GPE-R on locomotor hyperactivity caused by striatum damage, locomotor activity was traced for $60 \mathrm{~min}$ before and 1 day after ischemia, as described previously [33]. The apparatus was made of Plexiglas $(25 \times 20 \times 12 \mathrm{~cm})$ and locomotor activity was recorded with Photobeam Activity System-Home Cage (San Diego Instruments, San Diego, CA, USA).

\subsection{Tissue Processing}

Following spontaneous motor activity observation, animals were deeply anesthetized with a mixture of alfaxalone (Alfaxan, $75 \mathrm{mg} / \mathrm{kg}$; Careside, Seongnam, Korea) and xylazine (10 mg/kg; Bayer Korea, Seoul, Korea) 4 days after ischemia/reperfusion as a modified method $[38,39,45]$ because neuronal cell death and subsequent glial activation was mainly detected in the hippocampal CA1 region 4 days after ischemia. Thereafter, brain samples were obtained by transcardial perfusion with $0.1 \mathrm{M}$ phosphate-buffered saline ( $\mathrm{pH} 7.4)$, followed by $4 \%$ paraformaldehyde in $0.1 \mathrm{M}$ phosphate-buffer ( $\mathrm{pH} 7.4)$, as described previously [33,34]. Brain tissue was cryoprotected by overnight saturation with $30 \%$ sucrose. Coronal brain slices $(30 \mu \mathrm{m})$ located between 1.4 and $2.0 \mathrm{~mm}$ caudal to bregma in reference to a stereotaxic brain gerbil atlas [46], were obtained using a cryostat (Leica, Wetzlar, Germany). Five slices at $90-\mu \mathrm{m}$ intervals were immunohistochemically processed with the conventional avidin-biotin complex method and visualized with 3,3'-diaminobenzidine tetrachloride (Sigma). Primary antibodies were used as follows: mouse anti-neuronal nu- 
clei (NeuN) antibody (1:1000; EMD Millipore, Temecula, CA, USA) and rabbit anti-ionized calcium-binding adapter molecule 1 (Iba-1; 1:500; Wako, Osaka, Japan).

The number of NeuN-positive nuclei in the dorsal hippocampus was measured in the hippocampal CA1 region using an image analysis system (software: Optimas 6.5, CyberMetrics, Scottsdale, AZ, USA). Analysis of the Iba- 1 immunoreactivity in the hippocampal CA1 region was assessed by the optical density in 256-pixel gray levels. The hippocampal CA1 region was divided into 3 subregions such as stratum pyramidale, oriens, and radiatum. The optical density was measured in each subregion using ImageJ v. 1.80 software (National Institutes of Health) and results were transformed to a relative optical density $(\mathrm{ROD})=\log _{10}(256 /$ mean gray level $)$ as described in previous studies $[33,34]$.

\subsection{ELISA for Pro-Inflammatory Cytokines}

To measure changes in TNF- $\alpha$, IL-1 $\beta$, and IL-6 levels in the hippocampus, separate animals from the control, vehicle-treated ischemic, $30 \mathrm{mg} / \mathrm{kg}$ GPE-R-treated ischemic, and $300 \mathrm{mg} / \mathrm{kg}$ GPE-R-treated ischemic groups ( $n=7$ per group) were sacrificed with deep anesthesia with alfaxalone $(100 \mathrm{mg} / \mathrm{kg})$ and xylazine $(15 \mathrm{mg} / \mathrm{kg})$ and subsequent decapitation, and the extracted brains were used for enzyme-linked immunosorbent assay (ELISA) as described previously by our colleagues [47] with commercial kits (EMD Millipore, Billerica, MA, USA).

\subsection{Statistical Analysis}

Data were analyzed to check for significant differences between groups by one-way analyses of variance, followed by Bonferroni's post-hoc tests using GraphPad Prism 5.01 software (GraphPad Software, Inc., La Jolla, CA, USA). Level of significance was set at $p<0.05$.

\section{Results}

\subsection{Body Weights}

Gerbils showed similar body weight (65.93-67.04 g) before ischemia and body weight was slightly increased $(68.19 \mathrm{~g})$ in the control group, but ischemia-operated gerbils showed slightly decreases in body weight (62.48-64.95 g). However, there were no significant differences in body weights before and 4 days after ischemia in all groups (Figure 1).

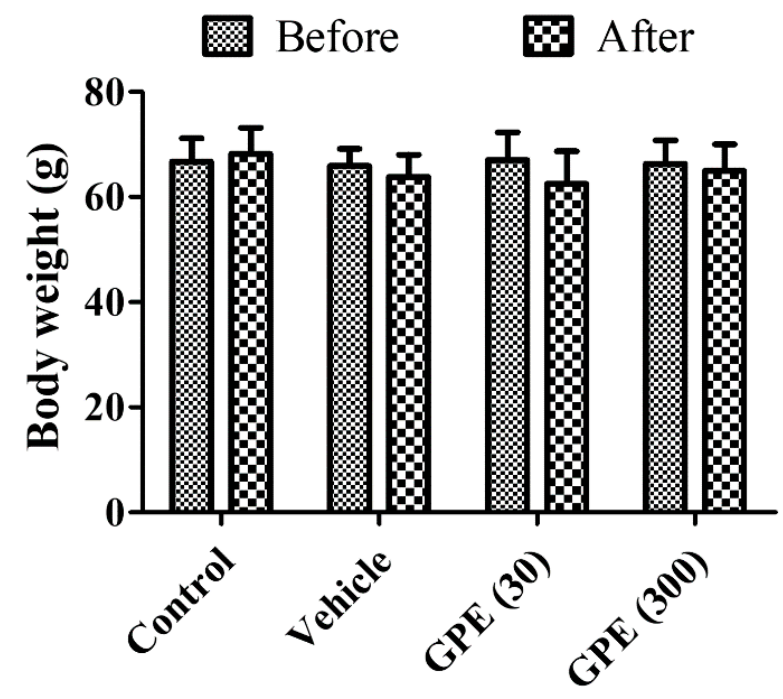

Figure 1. Body weight in the control, vehicle-treated ischemic (Vehicle), $30 \mathrm{mg} / \mathrm{kg}$ Gynura procumbens roots (GPE-R)-treated ischemic (GPE30), and $300 \mathrm{mg} / \mathrm{kg}$ GPE-R-treated ischemic (GPE300) groups. There are no significant changes in body weight before and after ischemia or GPE-R treatment. Error bars represent standard errors of the means. 


\subsection{Effects of GPE-R on Locomotor Activity before and 1 Day after Ischemia}

The distance traveled was measured to compare the locomotor hyperactivity among the groups, both before and one day after ischemia/reperfusion. In the control group, spontaneous motor activity showed no significant difference before and after sham surgery. In the vehicle-treated ischemic and $30 \mathrm{mg} / \mathrm{kg}$ GPE-R-treated ischemic groups, gerbils showed significantly higher locomotor hyperactivity 1 day after ischemia compared to one day before. In the vehicle-treated ischemic and $30 \mathrm{mg} / \mathrm{kg}$ GPE-R-treated ischemic groups, the distance traveled was 2.97 -fold and 2.82-fold one day after vs. before ischemia, respectively. In the $300 \mathrm{mg} / \mathrm{kg}$ GPE-R-treated ischemic group, locomotor activity was increased one day after ischemia; however, it showed significant lower levels compared to that in the vehicle-treated ischemic group (1.94-fold one day after ischemia vs. one day before ischemia, $p<0.001$ ) (Figure 2).

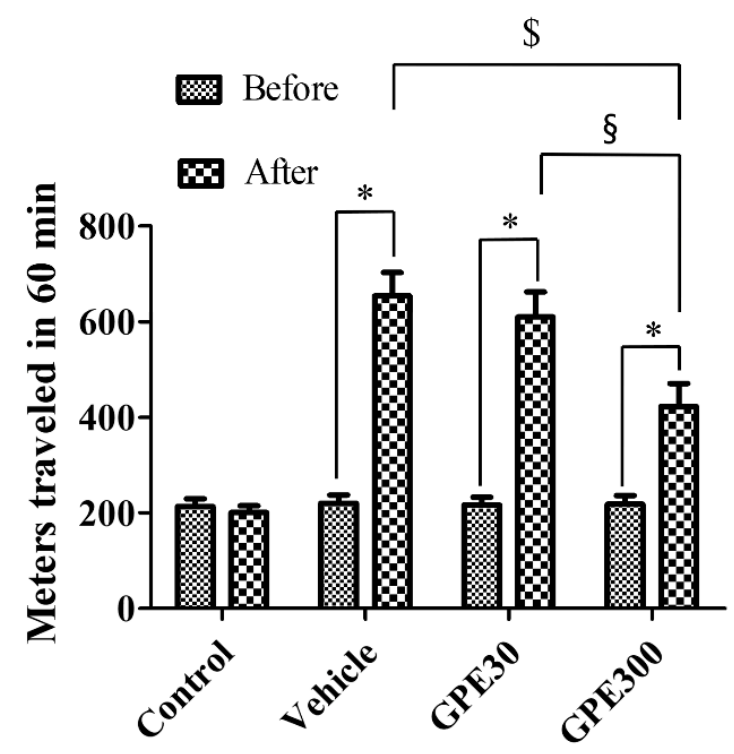

Figure 2. Locomotor activity in the control, vehicle-treated ischemic (Vehicle), $30 \mathrm{mg} / \mathrm{kg}$ GPE-Rtreated ischemic (GPE30), and $300 \mathrm{mg} / \mathrm{kg}$ GPE-R-treated ischemic (GPE300) groups. The total distance (meters) traveled in $60 \mathrm{~min}$ was observed 1 day before and after ischemia/reperfusion ( $n=7$ per group, ${ }^{*} p<0.05$ vs. the control group; ${ }^{\$} p<0.05$ vs. the vehicle group; ${ }^{\S} p<0.05$ vs. the GPE30 group). Error bars represent standard errors of the means.

\subsection{Effects of GPE-R on Ischemia-Induced Neuronal Death 4 Days after Ischemia}

In the control group, many NeuN-positive neurons were detected in the CA1 region four days after sham surgery (Figure $3 \mathrm{~A}$ ). In the vehicle-treated ischemic and $30 \mathrm{mg} / \mathrm{kg}$ GPE-R-treated ischemic groups, only a few NeuN-positive neurons were observed in the CA1 region four days after ischemia/reperfusion and most surviving neurons were identified as non-pyramidal cells, based on morphology and location (Figure 3B,C). In these groups, the percentage of NeuN-immunoreactive neurons was $5.56 \%$ and $5.50 \%$ of the control group, respectively (Figure 3E). In the $300 \mathrm{mg} / \mathrm{kg}$ GPE-R-treated ischemic group, some NeuN-positive neurons were observed in the stratum pyramidale of CA1 region (Figure $3 \mathrm{D}$ ) and the number of NeuN-immunoreactive neurons was significantly increased to $42.47 \%$ of the control group compared to that in the vehicle-treated group $(p<0.001)$ (Figure 3E). 


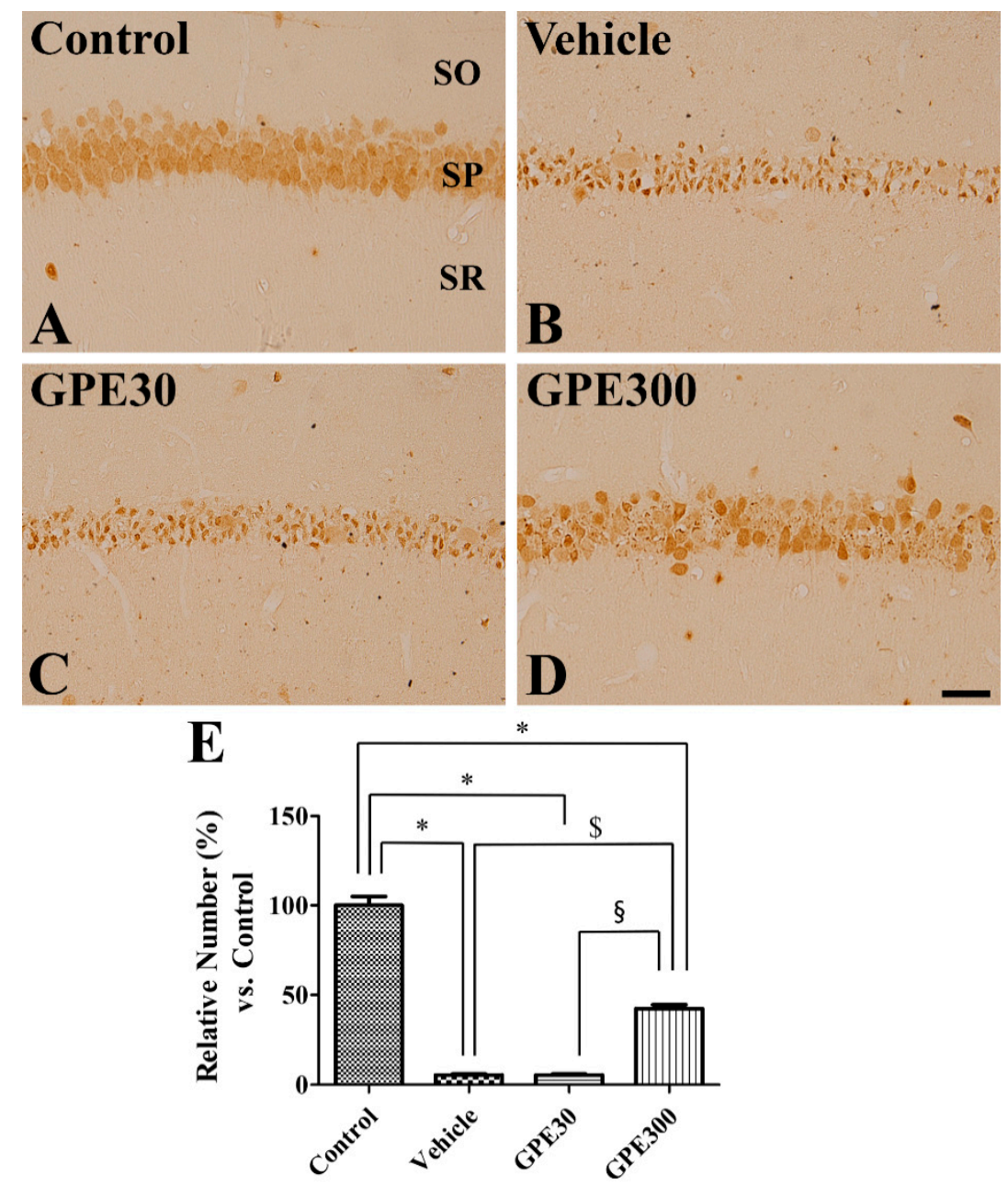

Figure 3. Immunohistochemistry for $\mathrm{NeuN}$ in the CA1 region of the control (A), vehicle-treated ischemic (Vehicle, B), $30 \mathrm{mg} / \mathrm{kg}$ GPE-R-treated ischemic (GPE30, C), and $300 \mathrm{mg} / \mathrm{kg}$ GPE-R-treated ischemic (GPE300, D) groups. SO, stratum oriens; SP, stratum pyramidale; SR; stratum radiatum. Scale bar $=50 \mu \mathrm{m}$. (E) The number of NeuN-immunoreactive neurons per section in the hippocampal CA1 region of each group compared with the control group, is shown $\left(n=7\right.$ per group, ${ }^{*} p<0.05$ vs. the control group; ${ }^{\$} p<0.05$ vs. the vehicle group; ${ }^{\S} p<0.05$ vs. the GPE30 group). Error bars represent standard errors of the means.

\subsection{Effects of GPE-R on Ischemia-Induced Activation of Microglia 4 Days after Ischemia}

In the control group, Iba-1 immunoreactive microglia were diffusely found in the CA1 region and had a morphology of a round soma with thin processes (Figure $4 \mathrm{~A}$ ). In the vehicle-treated ischemic and $30 \mathrm{mg} / \mathrm{kg}$ GPE-R-treated ischemic groups, Iba- 1 immunoreactivity was showed in microglia, which had hypertrophied somas with very short or no processes (phagocytic form) in the stratum pyramidale, while in the stratum oriens and radiatum, they showed hypertrophied somas with bushy processes (reactive form) (Figure $4 \mathrm{~B}, \mathrm{C}$ ). In these groups, Iba-1 immunoreactivity was significantly increased in the stratum pyramidale of CA1 region to 1334.1 and $1094.5 \%$ of the control group, respectively (Figure $4 \mathrm{E}$ ). In the stratum radiatum of CA1 region, Iba-1 immunoreactivity was significantly increased only in the vehicle-treated group compared to that in the control group, while in the stratum oriens, there were no significant differences on Iba- 1 immunoreactivity among groups (Figure 4E). In the $300 \mathrm{mg} / \mathrm{kg}$ GPE-R-treated ischemic group, there were few Iba-1-immunoreactive microglia in the phagocytic form in the stratum pyramidale, although many reactive microglia were present in the stratum oriens and radiatum (Figure 4D). In this group, significantly lower levels of Iba-1 immunoreactivity were de- 
tected in the stratum pyramidale of CA1 region compared to the vehicle-treated ischemic group (621.48\% of the control group) (Figure $4 \mathrm{E})$.

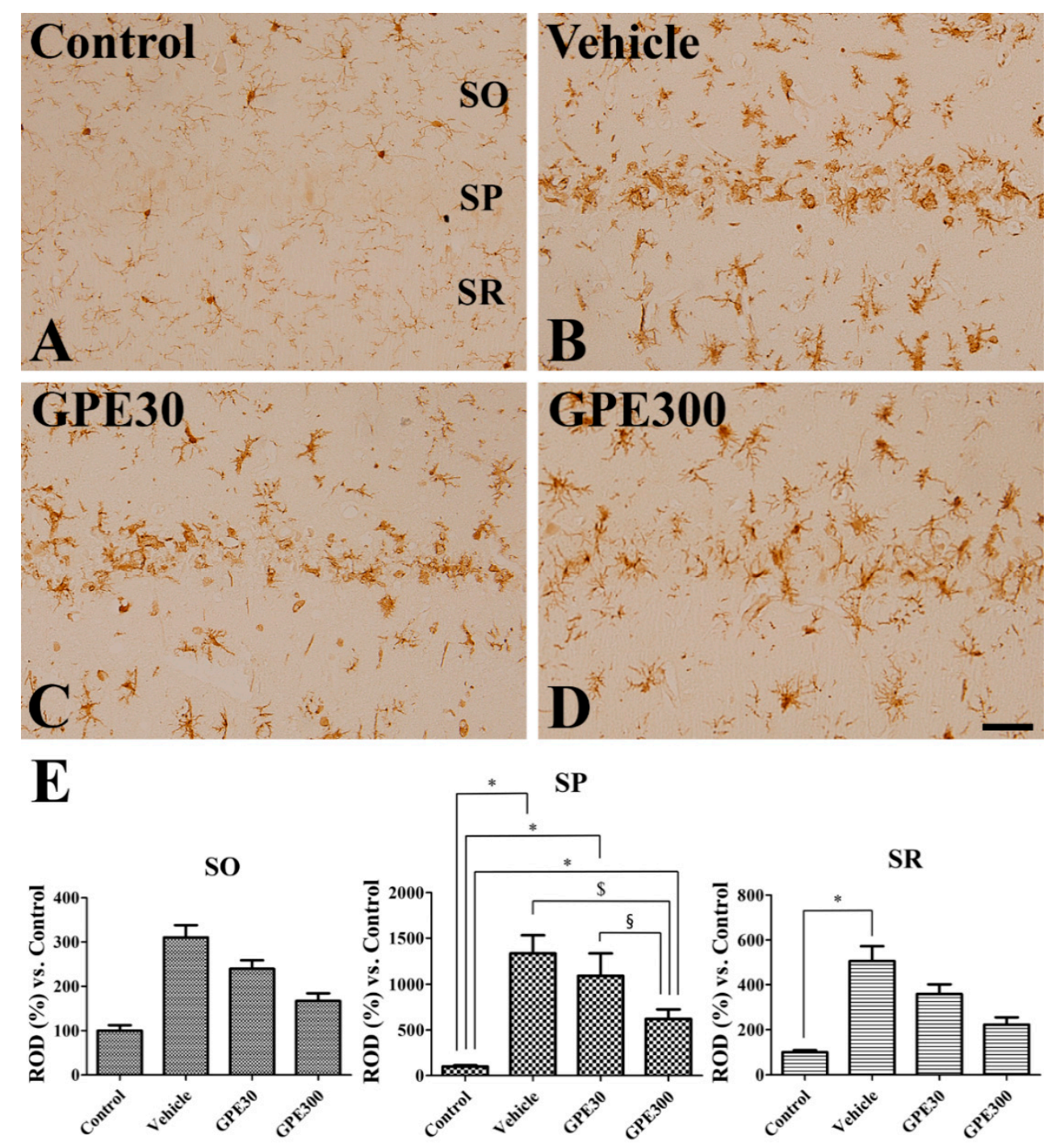

Figure 4. Immunohistochemistry for Iba-1 in the CA1 region of the control (A), vehicle-treated ischemic (Vehicle, B), $30 \mathrm{mg} / \mathrm{kg}$ GPE-R-treated ischemic (GPE30, C), and $300 \mathrm{mg} / \mathrm{kg}$ GPE-R-treated ischemic (GPE300, D) groups. SO, stratum oriens; SP, stratum pyramidale; SR; stratum radiatum. Scale bar $=50 \mu \mathrm{m}$. (E) ROD per section in the SO, SP, and SR of hippocampal CA1 region in each group compared with the control group, is shown ( $n=7$ per group, ${ }^{*} p<0.05$ vs. the control group; $\$ p<0.05$ vs. the vehicle group; $\S^{\S}<0.05$ vs. the GPE30 group). Error bars represent standard errors of the means.

\subsection{Effects of GPE-R on ISCHEMIA-Induced Release of Pro-Inflammatory Cytokines $6 \mathrm{~h}$ after Ischemia}

Six hours after ischemia/reperfusion, IL-6, IL-1 $\beta$, and TNF- $\alpha$ levels in the vehicletreated ischemic group were significantly increased in hippocampal homogenates compared to the control group. IL-6, IL-1 $\beta$, and TNF- $\alpha$ levels in the vehicle-treated ischemic group were 3.30-, 5.17-, and 24.72-fold of those in the control group, respectively. In the $30 \mathrm{mg} / \mathrm{kg}$ GPE-R-treated ischemic group, IL-6 ( $p=0.2477)$, IL-1 $\beta(p=0.2009)$, and TNF- $\alpha$ ( $p=0.5792)$ levels in the hippocampus were similar to those of the vehicle-treated ischemic group. In the $300 \mathrm{mg} / \mathrm{kg}$ GPE-R-treated ischemic group, IL-6 ( $p=0.0019), \mathrm{IL}-1 \beta(p=0.0165)$, and TNF- $\alpha(p<0.0001)$ levels were significantly decreased to about half of those of the vehicle-treated group. IL-6 ( $p=0.0206)$ and TNF- $\alpha(p=0.0003)$ levels were significantly 
decreased in $300 \mathrm{mg} / \mathrm{kg}$ GPE-R-treated ischemic group compared to that in the $30 \mathrm{mg} / \mathrm{kg}$ GPE-R-treated ischemic group, while IL-1 $\beta(p=0.2706)$ levels did not show any significant changes between 30 and $300 \mathrm{mg} / \mathrm{kg}$ GPE-R-treated ischemic group (Figure 5).
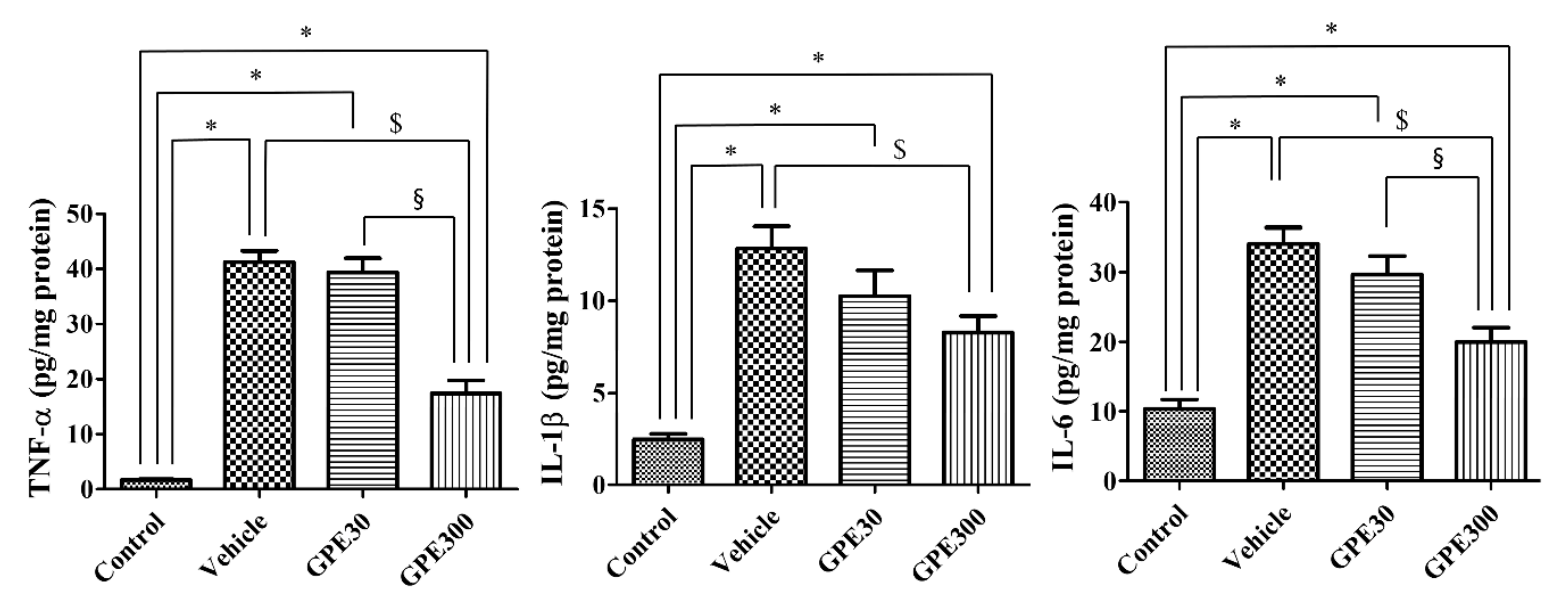

Figure 5. Levels of tumor necrosis factor- $\alpha$ (TNF- $\alpha$ ), interleukin (IL)-1 $\beta$, and IL-6 in the hippocampi of the control, vehicletreated ischemic (Vehicle), $30 \mathrm{mg} / \mathrm{kg}$ GPE-R-treated ischemic (GPE30), and $300 \mathrm{mg} / \mathrm{kg}$ GPE-R-treated ischemic (GPE300) groups ( $n=7$ per group, ${ }^{*} p<0.05$ vs. the control group; ${ }^{\$} p<0.05$ vs. the vehicle group; ${ }^{\S} p<0.05$ vs. the GPE30 group) are shown. Error bars represent standard errors of the means.

\section{Discussion}

Brain ischemia is the most severe type of stroke, and many studies have investigated its pathophysiology, molecular mechanisms, and potential therapeutic agents [48,49]. However, most studies have failed due to toxicity and side effects [17]. Medicinal plants have been studied as alternative preventive or therapeutic agents in various diseases including brain ischemia because of their minimal toxic effects [31,50-52].

In the present study, we selected GPE-R as a possible candidate to prevent the neuronal damage induced by ischemia, because GPE has various functional components including chlorogenic acid, quercetin-3-0-rhamnosyl, kaempferol-3-0-glucoside, and kaempferol3 -0-rutinoside $[37,53]$. We assessed the neuroprotective effects of GPE-R in gerbils one day after ischemia based on their total distance traveled, which had been proved to be increased after ischemic hippocampal cell damage in previous studies [54,55]. However, the locomotor activity is decreased to basal levels seven days after ischemia [56,57]. Hence, the locomotor activity test is a useful predictable model to assess hippocampal damage early [57]. Administration of $300 \mathrm{mg} / \mathrm{kg}$ GPE-R significantly reduced the distance traveled one day after ischemia/reperfusion compared to both vehicle-treated ischemic and $30 \mathrm{mg} / \mathrm{kg}$ GPE-R-treated ischemic groups. We also confirmed the neuroprotective effects of GPE-R against ischemic damage in the hippocampal CA1 region by NeuN immunohistochemistry. Most pyramidal cells showed neuronal death and surviving neurons were relatively few (about $4-10 \%$ in total). In this regard, we conducted NeuN staining to detect surviving neurons in the hippocampal CA1 region. Administration of $300 \mathrm{mg} / \mathrm{kg}$, but not $30 \mathrm{mg} / \mathrm{kg}$, GPE-R significantly reduced CA1 neuronal death four days after ischemia. GPE has high phenolic content and is a potential source of treatment for various diseases [19]. Furthermore, extracts from GPE-S mitigated ethanol-induced lipid accumulation in the livers of mice [37] and treatment with GPE-L significantly ameliorated ultraviolet B-induced matrix metalloproteinase-1 (MMP-1) expression in the culture medium of human dermal fibroblasts [27]. However, this study provides new insight that GPE-R has in vivo neuroprotective effects against ischemic damage in gerbils, although one poster presentation demonstrated the neuroprotective effects of GPE against glutamate-induced neurotoxicity in HT22 cells by modulation of intracellular calcium, reactive oxygen species levels, and mitochondrial membrane potential level [58]. 
Ischemia-induced reactive microglia produce and release neurotoxic molecules and pro-inflammatory cytokines [59,60]. In the present study, administration of $300 \mathrm{mg} / \mathrm{kg}$ GPE-R significantly reduced the phagocytic form of microglia in the stratum pyramidale of CA1 as well as the reactive form of microglia in the stratum oriens and radiatum. In addition, we observed the significant reduction of pro-inflammatory cytokines such as IL-6, IL-1 $\beta$, and TNF- $\alpha$ in hippocampal homogenates $6 \mathrm{~h}$ after ischemia. We observed the levels of IL-6, IL-1 $\beta$, and TNF- $\alpha$ in the hippocampus $6 \mathrm{~h}$ after ischemia because these pro-inflammatory cytokines are increased biphasically, with a prominent increase at this early period after ischemia [61,62]. In addition, nuclear factor $\mathrm{kB}(\mathrm{NF}-\mathrm{kB})$ is a transcription factor involved in the regulation of the induction of pro-inflammatory genes such as IL-1, IL-2, IL-6, IL-8, and TNF- $\alpha$, and functions in both innate and adaptive immune cells [63]. GPE has been shown to inhibit the nuclear transfer of NF-KB [64] as well as the release of pro-inflammatory cytokines such as IL-6 and IL-8 in human HaCat keratinocytes [27]. GPE also decreases inflammatory response stimulated by lipopolysaccharide (LPS) by inhibiting nitric oxide production and inducible nitric oxide synthase expression in RAW 264.7 cells [65]. Essential oils from Gynura procumbens have shown anti-inflammatory effects by inhibiting overexpression of COX-2 and reducing migration of RAW 264.7 macrophages in cell culture [66]. In addition, GPE also has vasodilatory effects via the inhibition of angiotensin converting enzyme [22], bradykinin [67], and calcium channel [68], which play an important role in neuronal death induced by ischemia in gerbils $[69,70]$.

Another possible mechanism implicated in GPR neuroprotective activity against ischemic damage is functional component-mediated neuroprotection. Indeed, GPE contains chlorogenic acid, quercetin-3-0-rhamnosyl, kaempferol-3-0-glucoside, and kaempferol-3-0rutinoside [37,53]. Intraperitoneal injection of $30 \mathrm{mg} / \mathrm{kg}$ chlorogenic acid reduces brain and blood-brain barrier damage by inhibition of MMP-2 and MMP-9 [71]. Kaempferol protects neurons from ischemic damage by reducing nitrosative-oxidative stress, caspase- 9 activity, and poly-(ADP-ribose) polymerase degradation [72]. In addition, quercetin ameliorates neuronal death induced by focal and transient forebrain ischemia via anti-oxidative and anti-inflammatory pathways [73,74]. However, the active ingredients responsible for the neuroprotective effects of GPE-R are still known and remain to be elucidated.

In summary, the pretreatment with GPE-R significantly promotes the survival of neurons in the hippocampal CA1 region after ischemia/reperfusion by reducing reactive microglia and pro-inflammatory cytokines such as IL-6, IL-1 $\beta$, and TNF- $\alpha$. GPE-R can be a candidate functional food to protect neurons from ischemic damage.

Author Contributions: Conceptualization, W.K., S.Y.C., and I.K.H.; methodology, W.K., H.Y.J., H.J.K., and K.R.H.; data curation, W.K. and D.Y.Y.; writing-original draft preparation, W.K.; writingreview and editing, D.W.K., Y.S.Y., S.Y.C., and I.K.H. All authors have read and agreed to the published version of the manuscript.

Funding: This research was supported by Basic Science Research Program through the National Research Foundation of Korea (NRF) funded by the Ministry of Education (2019R1A6A1A11036849). In addition, the current study was supported by the Research Institute for Veterinary Science of Seoul National University.

Institutional Review Board Statement: The study was conducted according to the guidelines of the Declaration of Helsinki, and approved by the Institutional Animal Care and Use Committee of Seoul National University (protocol code SNU-170807-11 and date of approval: 13/12/2017).

Informed Consent Statement: Not applicable.

Data Availability Statement: The datasets and supporting materials generated during and/or analyzed during the current study are available from the corresponding author on reasonable request.

Conflicts of Interest: The authors declare no competing interests. 


\section{References}

1. Bertolino, G.; de Araujo, F.L.; Souza, H.C.; Coimbra, N.C.; de Araujo, J.E. Neuropathology and behavioral impairments after bilateral global ischemia surgery and exposure to static magnetic field: Evidence in the motor cortex, the hippocampal CA1 region and the neostriatum. Int. J. Radiat. Biol. 2013, 89, 595-601. [CrossRef] [PubMed]

2. Wahul, A.B.; Joshi, P.C.; Kumar, A.; Chakravarty, S. Transient global cerebral ischemia differentially affects cortex, striatum and hippocampus in Bilateral Common Carotid Arterial occlusion (BCCAo) mouse model. J. Chem. Neuroanat. 2018, 92, 1-15. [CrossRef] [PubMed]

3. Duszczyk, M.; Ziembowicz, A.; Gadamski, R.; Wieronska, J.M.; Smialowska, M.; Lazarewicz, J.W. Changes in the NPY immunoreactivity in gerbil hippocampus after hypoxic and ischemic preconditioning. Neuropeptides 2009, 43, 31-39. [CrossRef] [PubMed]

4. Levine, S.; Payan, H. Effects of ischemia and other procedures on the brain and retina of the gerbil (Meriones unguiculatus). Exp. Neurol. 1966, 16, 255-262. [CrossRef]

5. Andersen, M.B.; Zimmer, J.; Sams-Dodd, F. Postischemic hyperactivity in the Mongolian gerbil correlates with loss of hippocampal neurons. Behav. Neurosci. 1997, 111, 1205-1216. [CrossRef] [PubMed]

6. Kondo, T.; Yoshida, S.; Nagai, H.; Takeshita, A.; Mino, M.; Morioka, H.; Nakajima, T.; Kusakabe, K.T.; Okada, T. Transient forebrain ischemia induces impairment in cognitive performance prior to extensive neuronal cell death in Mongolian gerbil (Meriones unguiculatus). J. Vet. Sci. 2018, 19, 505-511. [CrossRef] [PubMed]

7. Katsuta, K.; Umemura, K.; Ueyama, N.; Matsuoka, N. Pharmacological evidence for a correlation between hippocampal CA1 cell damage and hyperlocomotion following global cerebral ischemia in gerbils. Eur. J. Pharmacol. 2003, 467, 103-109. [CrossRef]

8. Kuroiwa, T.; Bonnekoh, P.; Hossmann, K.A. Locomotor hyperactivity and hippocampal CA1 injury after transient forebrain ischemia of gerbils. Neurosci. Lett. 1991, 122, 141-144. [CrossRef]

9. Mileson, B.E.; Schwartz, R.D. The use of locomotor activity as a behavioral screen for neuronal damage following transient forebrain ischemia in gerbils. Neurosci. Lett. 1991, 128, 71-76. [CrossRef]

10. Wang, Q.; Tompkins, K.D.; Simonyi, A.; Korthuis, R.J.; Sun, A.Y.; Sun, G.Y. Apocynin protects against global cerebral ischemiareperfusion-induced oxidative stress and injury in the gerbil hippocampus. Brain Res. 2006, 1090, 182-189. [CrossRef]

11. Velimirović, M.; Jevtić Dožudić, G.; Selaković, V.; Stojković, T.; Puškaš, N.; Zaletel, I.; Živković, M.; Dragutinović, V.; Nikolić, T.; Jelenković, A.; et al. Effects of vitamin D3 on the NADPH oxidase and matrix metalloproteinase 9 in an animal model of global cerebral ischemia. Oxid. Med. Cell. Longev. 2018, 2018, 3273654. [CrossRef] [PubMed]

12. Streit, W.J.; Graeber, M.B.; Kreutzberg, G.W. Functional plasticity of microglia: A review. Glia 1988, 1, 301-307. [CrossRef] [PubMed]

13. Qu, Y.; Zhang, H.L.; Zhang, X.P.; Jiang, H.L. Arachidonic acid attenuates brain damage in a rat model of ischemia/reperfusion by inhibiting inflammatory response and oxidative stress. Hum. Exp. Toxicol. 2018, 37, 135-141. [CrossRef] [PubMed]

14. Wang, Q.; Tang, X.N.; Yenari, M.A. The inflammatory response in stroke. J. Neuroimmunol. 2007, 184, 53-68. [CrossRef] [PubMed]

15. Godefroy, O.; Fickl, A.; Roussel, M.; Auribault, C.; Bugnicourt, J.M.; Lamy, C.; Canaple, S.; Petitnicolas, G. Is the Montreal Cognitive Assessment superior to the Mini-Mental State Examination to detect poststroke cognitive impairment? A study with neuropsychological evaluation. Stroke 2011, 42, 1712-1716. [CrossRef] [PubMed]

16. Mijajlović, M.D.; Pavlović, A.; Brainin, M.; Heiss, W.D.; Quinn, T.J.; Ihle-Hansen, H.B.; Hermann, D.M.; Assayag, E.B.; Richard, E.; Thiel, A.; et al. Post-stroke dementia-A comprehensive review. BMC Med. 2017, 15, 11. [CrossRef]

17. Ciccone, A.; Valvassori, L.; Nichelatti, M.; Sgoifo, A.; Ponzio, M.; Sterzi, R.; Boccardi, E. SYNTHESIS Expansion Investigators. Endovascular treatment for acute ischemic stroke. N. Engl. J. Med. 2013, 368, 904-913. [CrossRef]

18. Krishnan, V.; Ahmad, S.; Mahmood, M. Antioxidant potential in different parts and callus of Gynura procumbens and different parts of Gynura bicolor. Biomed. Res. Int. 2015, 2015, 147909. [CrossRef]

19. Rosidah Yam, M.F.; Sadikun, A.; Ahmad, M.; Akowuah, G.A.; Asmawi, M.Z. Toxicology evaluation of standardized methanol extract of Gynura procumbens. J. Ethnopharmacol. 2009, 123, 244-249. [CrossRef]

20. Kim, M.J.; Lee, H.J.; Wiryowidagdo, S.; Kim, H.K. Antihypertensive effects of Gynura procumbens extract in spontaneously hypertensive rats. J. Med. Food 2006, 9, 587-590. [CrossRef]

21. Iskander, M.N.; Song, Y.; Coupar, I.M.; Jiratchariyakul, W. Antiinflammatory screening of the medicinal plant Gynura procumbens. Plant Foods Hum. Nutr. 2002, 57, 233-244. [CrossRef] [PubMed]

22. Hoe, S.Z.; Kamaruddin, M.Y.; Lam, S.K. Inhibition of angiotensin-converting enzyme activity by a partially purified fraction of Gynura procumbens in spontaneously hypertensive rats. Med. Princ. Pract. 2007, 16, 203-208. [CrossRef] [PubMed]

23. Zhang, X.F.; Tan, B.K. Effects of an ethanolic extract of Gynura procumbens on serum glucose, cholesterol and triglyceride levels in normal and streptozotocin-induced diabetic rats. Singap. Med. J. 2000, 41, 9-13.

24. Algariri, K.; Meng, K.Y.; Atangwho, I.J.; Asmawi, M.Z.; Sadikun, A.; Murugaiyah, V.; Ismail, N. Hypoglycemic and antihyperglycemic study of Gynura procumbens leaf extracts. Asian Pac. J. Trop. Biomed. 2013, 3, 358-366. [CrossRef]

25. Hoe, S.Z.; Lee, C.N.; Mok, S.L.; Kamaruddin, M.Y.; Lam, S.K. Gynura procumbens Merr. decreases blood pressure in rats by vasodilatation via inhibition of calcium channels. Clinics (Sao Paulo) 2011, 66, 143-150. [CrossRef] [PubMed]

26. Abrika, O.S.; Yam, M.F.; Asmawi, M.Z.; Sadikun, A.; Dieng, H.; Hussain, E.A. Effects of extracts and fractions of Gynura procumbens on rat atrial contraction. J. Acupunct. Meridian Stud. 2013, 6, 199-207. [CrossRef]

27. Kim, J.; Lee, C.W.; Kim, E.K.; Lee, S.J.; Park, N.H.; Kim, H.S.; Kim, H.K.; Char, K.; Jang, Y.P.; Kim, J.W. Inhibition effect of Gynura procumbens extract on UV-B-induced matrix-metalloproteinase expression in human dermal fibroblasts. J. Ethnopharmacol. 2011, 137, 427-433. [CrossRef] 
28. Ahmad Nazri, K.A.; Fauzi, N.M.; Buang, F.; Mohd Saad, Q.H.; Husain, K.; Jantan, I.; Jubri, Z. Gynura procumbens standardised extract reduces cholesterol levels and modulates oxidative status in postmenopausal rats fed with cholesterol diet enriched with repeatedly heated palm oil. Evid. Based Complement. Alternat. Med. 2019, 2019, 7246756. [CrossRef]

29. Iqbal, Z.; Bello, I.; Asmawi, M.Z.; Al-Mansoub, M.A.; Ahmad, A.; Jabeen, Q.; Fei, Y.M. Vasorelaxant activities and the underlying pharmacological mechanisms of Gynura procumbens Merr. leaf extracts on rat thoracic aorta. Inflammopharmacology 2019, 27, 421-431. [CrossRef]

30. Zahra, A.A.; Kadir, F.A.; Mahmood, A.A.; Al Hadi, A.A.; Suzy, S.M.; Sabri, S.Z.; Latifl, I.I.; Katuly, K.A. Acute toxicity study and wound healing potential of Gynura procumbens leaf extract in rats. J. Med. Plants Res. 2011, 5, 2551-2558.

31. Tan, H.L.; Chan, K.G.; Pusparajah, P.; Lee, L.H.; Goh, B.H. Gynura procumbens: An overview of the biological activities. Front. Pharmacol. 2016, 7, 52. [CrossRef] [PubMed]

32. Mirza, M.A.; Ritzel, R.; Xu, Y.; McCullough, L.D.; Liu, F. Sexually dimorphic outcomes and inflammatory responses in hypoxicischemic encephalopathy. J. Neuroinflamm. 2015, 12, 32. [CrossRef] [PubMed]

33. Yoo, D.Y.; Jung, H.Y.; Nam, S.M.; Kim, J.W.; Choi, J.H.; Kwak, Y.G.; Yoo, M.; Lee, S.; Yoon, Y.S.; Hwang, I.K. Valeriana officinalis extracts ameliorate neuronal damage by suppressing lipid peroxidation in the gerbil hippocampus following transient cerebral ischemia. J. Med. Food 2015, 18, 642-647. [CrossRef]

34. Jung, H.Y.; Kim, W.; Hahn, K.R.; Kang, M.S.; Kim, T.H.; Kwon, H.J.; Nam, S.M.; Chung, J.Y.; Choi, J.H.; Yoon, Y.S.; et al. Pyridoxine deficiency exacerbates neuronal damage after ischemia by increasing oxidative stress and reduces proliferating cells and neuroblasts in the gerbil hippocampus. Int. J. Mol. Sci. 2020, 21, 5551.

35. Kilkenny, C.; Browne, W.J.; Cuthill, I.C.; Emerson, M.; Altman, D.G. Improving bioscience research reporting: The ARRIVE guidelines for reporting animal research. PLoS Biol. 2010, 8, e1000412. [CrossRef]

36. Kamaruzaman, K.A.; Aizat, W.M.; Mat Noor, M. Gynura procumbens improved fertility of diabetic rats: Preliminary study of sperm proteomic. Evid. Based Complement. Alternat. Med. 2018, 2018, 9201539. [CrossRef]

37. Li, X.J.; Mu, Y.M.; Li, T.T.; Yang, Y.L.; Zhang, M.T.; Li, Y.S.; Zhang, W.K.; Tang, H.B.; Shang, H.C. Gynura procumbens reverses acute and chronic ethanol-induced liver steatosis through MAPK/SREBP-1c-dependent and -independent pathways. J. Agric. Food Chem. 2015, 63, 8460-8471.

38. De Segura, I.A.; de la Víbora, J.B.; Criado, A. Determination of the minimum alveolar concentration for halothane, isoflurane and sevoflurane in the gerbil. Lab. Anim. 2009, 43, 239-242.

39. Erickson, R.L.; Blevins, C.E.; Souza Dyer, C.; Marx, J.O. Alfaxalone-xylazine anesthesia in laboratory mice (Mus musculus). J. Am. Assoc. Lab. Anim. Sci. 2019, 58, 30-39.

40. Goyagi, T.; Toung, T.J.; Kirsch, J.R.; Traystman, R.J.; Koehler, R.C.; Hurn, P.D.; Bhardwaj, A. Neuroprotective kappa-opioid receptor agonist BRL 52537 attenuates ischemia-evoked nitric oxide production in vivo in rats. Stroke 2003, 34, 1533-1538.

41. Wang, S.Y.; Duan, Y.L.; Zhao, B.; Wang, X.R.; Zhao, Z.; Zhang, G.M. Effect of delta opioid receptor activation on spatial cognition and neurogenesis in cerebral ischemic rats. Neurosci. Lett. 2016, 620, 20-26. [CrossRef] [PubMed]

42. Choi, I.Y.; Hwang, L.; Jin, J.J.; Ko, I.G.; Kim, S.E.; Shin, M.S.; Shin, K.M.; Kim, C.J.; Park, S.W.; Han, J.H.; et al. Dexmedetomidine alleviates cerebral ischemia-induced short-term memory impairment by inhibiting the expression of apoptosis-related molecules in the hippocampus of gerbils. Exp. Ther. Med. 2017, 13, 107-116. [CrossRef] [PubMed]

43. Pétrault, M.; Gautier, S.; Bérézowski, V.; Ouk, T.; Bastide, M.; Pétrault, O.; Bordet, R. Neither nefopam nor acetaminophen can be used as postoperative analgesics in a rat model of ischemic stroke. Fundam. Clin. Pharmacol. 2017, 31, 194-200. [CrossRef] [PubMed]

44. Du Sert, N.P.; Alfieri, A.; Allan, S.M.; Carswell, H.V.; Deuchar, G.A.; Farr, T.D.; Flecknell, P.; Gallagher, L.; Gibson, C.L.; Haley, M.J.; et al. The IMPROVE Guidelines (Ischaemia Models: Procedural Refinements Of In Vivo Experiments). J. Cereb. Blood Flow Metab. 2017, 37, 3488-3517. [CrossRef]

45. Flecknell, P.A. Laboratory Animal Anaesthesia; Academic Press: Amsterdam, The Netherland, 2016; pp. $210-213$.

46. Loskota, W.A.; Lomax, P.; Verity, M.A. A Stereotaxic Atlas of the Mongolian Gerbil Brain (Meriones Unguiculatus); Ann Arbor Science Publishers Inc.: Ann Arbor, MI, USA, 1974.

47. Moon, S.M.; Choi, G.M.; Yoo, D.Y.; Jung, H.Y.; Yim, H.S.; Kim, D.W.; Hwang, I.K.; Cho, B.M.; Chang, I.B.; Cho, S.M.; et al. Differential effects of pioglitazone in the hippocampal CA1 region following transient forebrain ischemia in low- and high-fat diet-fed gerbils. Neurochem. Res. 2015, 40, 1063-1073. [CrossRef]

48. Tuttolomondo, A.; Pecoraro, R.; Arnao, V.; Maugeri, R.; Iacopino, D.G.; Pinto, A. Developing drug strategies for the neuroprotective treatment of acute ischemic stroke. Expert. Rev. Neurother. 2015, 15, 1271-1284. [CrossRef]

49. Sanganalmath, S.K.; Gopal, P.; Parker, J.R.; Downs, R.K.; Parker, J.C., Jr.; Dawn, B. Global cerebral ischemia due to circulatory arrest: Insights into cellular pathophysiology and diagnostic modalities. Mol. Cell. Biochem. 2017, 426, 111-127. [CrossRef]

50. Chun, H.S.; Kim, J.M.; Choi, E.H.; Chang, N. Neuroprotective effects of several Korean medicinal plants traditionally used for stroke remedy. J. Med. Food 2008, 11, 246-251. [CrossRef]

51. Rodrigues, F.T.S.; de Sousa, C.N.S.; Ximenes, N.C.; Almeida, A.B.; Cabral, L.M.; Patrocínio, C.F.V.; Silva, A.H.; Leal, L.K.A.M.; Honório Júnior, J.E.R.; Macedo, D.; et al. Effects of standard ethanolic extract from Erythrina velutina in acute cerebral ischemia in mice. Biomed. Pharmacother. 2017, 96, 1230-1239. [CrossRef]

52. Hwang, S.N.; Kim, J.C.; Bhuiyan, M.I.H.; Kim, J.Y.; Yang, J.S.; Yoon, S.H.; Yoon, K.D.; Kim, S.Y. Black rice (Oryza sativa L., Poaceae) extract reduces hippocampal neuronal cell death induced by transient global cerebral ischemia in mice. Exp. Neurobiol. 2018, 27, 129-138. [CrossRef] 
53. Akowuah, G.A.; Sadikun, A.; Mariam, A. Flavonoid identification and hypoglycaemic studies of the butanol fraction from Gynura procumbens. Pharm. Biol. 2002, 40, 405-410. [CrossRef]

54. Janać, B.; Radenović, L.; Selaković, V.; Prolić, Z. Time course of motor behavior changes in Mongolian gerbils submitted to different durations of cerebral ischemia. Behav. Brain Res. 2006, 175, 362-373. [CrossRef] [PubMed]

55. Park, J.H.; Kim, Y.H.; Ahn, J.H.; Choi, S.Y.; Hong, S.; Kim, S.K.; Kang, I.J.; Kim, Y.M.; Lee, T.K.; Won, M.H.; et al. Atomoxetine protects against NMDA receptor-mediated hippocampal neuronal death following transient global cerebral ischemia. Curr. Neurovasc. Res. 2017, 14, 158-168. [CrossRef] [PubMed]

56. Gerhardt, S.C.; Boast, C.A. Motor activity changes following cerebral ischemia in gerbils are correlated with the degree of neuronal degeneration in hippocampus. Behav. Neurosci. 1988, 102, 301-303, 328. [CrossRef]

57. Ramos-Zúñiga, R.; Gómez, P.U.; Navarro Ruiz, A.; de Luquín, A.S.; García-Estrada, J. Locomotor activity is a predictive test after global ischemia-reperfusion in Mongolian gerbils. Minim. Invasive Neurosurg. 2008, 51, 87-90.

58. Hyeon, W.L.; Ga, H.R.; Woo, S.Y.; Choong, J.M. Gynura procumbens (Lour.) Merr inhibits the glutamate induced toxicity in neuronal cell lines. Plant. Med. Int. Open 2017, 4, S1-S202.

59. Wang, Y.; Ge, P.; Yang, L.; Wu, C.; Zha, H.; Luo, T.; Zhu, Y. Protection of ischemic post conditioning against transient focal ischemia-induced brain damage is associated with inhibition of neuroinflammation via modulation of TLR2 and TLR4 pathways. J. Neuroinflamm. 2014, 11, 15. [CrossRef]

60. Zeng, W.X.; Han, Y.L.; Zhu, G.F.; Huang, L.Q.; Deng, Y.Y.; Wang, Q.S.; Jiang, W.Q.; Wen, M.Y.; Han, Q.P.; Xie, D.; et al. Hypertonic saline attenuates expression of Notch signaling and proinflammatory mediators in activated microglia in experimentally induced cerebral ischemia and hypoxic BV-2 microglia. BMC Neurosci. 2017, 18, 32.

61. Lavine, S.D.; Hofman, F.M.; Zlokovic, B.V. Circulating antibody against tumor necrosis factor-alpha protects rat brain from reperfusion injury. J. Cereb. Blood Flow Metab. 1998, 18, 52-58.

62. Saito, K.; Suyama, K.; Nishida, K.; Sei, Y.; Basile, A.S. Early increases in TNF- $\alpha$, IL-6 and IL-1 $\beta$ levels following transient cerebral ischemia in gerbil brain. Neurosci. Lett. 1996, 206, 149-152.

63. Umezawa, K.; Ariga, A.; Matsumoto, N. Naturally occurring and synthetic inhibitors of NF-kappaB functions. Anticancer Drug Des. 2000, 15, 239-244. [PubMed]

64. Wang, H.; Zhou, J.W.; Fu, D.H.; Zhou, Y.; Cheng, W.Z.; Liu, Z.L. Gynura procumbens ethanolic extract suppresses osteosarcoma cell proliferation and metastasis in vitro. Oncol. Lett. 2013, 6, 113-117. [CrossRef] [PubMed]

65. Ning, T.J.; Yusoff, S.D.; Jubri, Z.; Buang, F.; Song, T.Z.; Budiono, A.; Jantan, I.; Dianita, R.; Kumolosasi, E.; Azmi, N.; et al. Inhibitory Effects of Gynura procumbens ethanolic extract on nitric oxide production and inducible nitric oxide synthase (iNOS) protein. Sains Malays. 2019, 48, 1737-1744.

66. Huang, X.L.; Li, X.J.; Qin, Q.F.; Li, Y.S.; Zhang, W.K.; Tang, H.B. Anti-inflammatory and antinociceptive effects of active ingredients in the essential oils from Gynura procumbens, a traditional medicine and a new and popular food material. J. Ethnopharmacol. 2019, 239, 111916. [CrossRef] [PubMed]

67. Poh, T.F.; Ng, H.K.; Hoe, S.Z.; Lam, S.K. Gynura procumbens causes vasodilation by inhibiting angiotensin II and enhancing bradykinin actions. J. Cardiovasc. Pharmacol. 2013, 61, 378-384. [CrossRef] [PubMed]

68. Ng, H.K.; Poh, T.F.; Lam, S.K.; Hoe, S.Z. Potassium channel openers and prostacyclin play a crucial role in mediating the vasorelaxant activity of Gynura procumbens. BMC Complement. Altern. Med. 2013, 13, 188. [CrossRef]

69. Zapater, P.; Moreno, J.; Horga, J.F. Neuroprotection by the novel calcium antagonist PCA50938, nimodipine and flunarizine, in gerbil global brain ischemia. Brain Res. 1997, 772, 57-62.

70. Fernandez, L.A.; Spencer, D.D.; Kaczmar, T., Jr. Angiotensin II decreases mortality rate in gerbils with unilateral carotid ligation. Stroke 1986, 17, 82-85. [CrossRef]

71. Lee, K.; Lee, J.S.; Jang, H.J.; Kim, S.M.; Chang, M.S.; Park, S.H.; Kim, K.S.; Bae, J.; Park, J.W.; Lee, B.; et al. Chlorogenic acid ameliorates brain damage and edema by inhibiting matrix metalloproteinase- 2 and 9 in a rat model of focal cerebral ischemia. Eur. J. Pharmacol. 2012, 689, 89-95. [CrossRef]

72. López-Sánchez, C.; Martín-Romero, F.J.; Sun, F.; Luis, L.; Samhan-Arias, A.K.; García-Martínez, V.; Gutiérrez-Merino, C. Blood micromolar concentrations of kaempferol afford protection against ischemia/reperfusion-induced damage in rat brain. Brain Res. 2007, 1182, 123-137.

73. Hwang, I.K.; Lee, C.H.; Yoo, K.Y.; Choi, J.H.; Park, O.K.; Lim, S.S.; Kang, I.J.; Kwon, D.Y.; Park, J.; Yi, J.S.; et al. Neuroprotective effects of onion extract and quercetin against ischemic neuronal damage in the gerbil hippocampus. J. Med. Food 2009, 12, 990-995. [CrossRef] [PubMed]

74. Wang, C.P.; Shi, Y.W.; Tang, M.; Zhang, X.C.; Gu, Y.; Liang, X.M.; Wang, Z.W.; Ding, F. Isoquercetin ameliorates cerebral impairment in focal ischemia through anti-oxidative, anti-inflammatory, and anti-apoptotic effects in primary culture of rat hippocampal neurons and hippocampal CA1 region of rats. Mol. Neurobiol. 2017, 54, 2126-2142. [CrossRef] [PubMed] 